\title{
Laboratuvarın Sesin Nesnel Parametreleri Açısından Değerlendirilmesi: KTÜ Örneği
}

\author{
Mustafa KAVRAZ ${ }^{*}$, Öznur KABİL ${ }^{2}$ \\ Geliş / Received: 17/07/2019 \\ Revize / Revised: 10/12/2019 \\ Kabul / Accepted: 03/01/2020 \\ ÖZ \\ Çalışma kapsamında, KTÜ Fizik Bölümü Bilgisayar Laboratuvarı ile Kimya Bölümü Analitik Kimya \\ Laboratuvarı akustik açıdan incelenmiştir. Öncelikle mekanların mevcut durumları için akustik \\ değerlendirmeler, sesin nesnel parametrelerinden; reverberasyon süresi (RT), erken düşme süresi (EDT), \\ belirginlik $\left(\mathrm{D}_{50}\right)$, sesin anlaşılabilirlik indeksine (STI) göre yapılmıştır. Çalışmada üç boyutlu simülasyon tekniği \\ yöntemi uygulanmış olup simülasyon programı olarak ODEON version 10 Acoustic Software kullanılmıştır. Üç \\ boyutlu modelin hazırlanması ise SketchUp8'de gerçekleştirilmiştir. Akustik açıdan optimum aralıklar dışında \\ kalan değerlerin optimum düzeye getirilmesi için mekanların yüzeylerinde malzeme değişiklikleri yapılmış ve \\ tüm nesnel parametreler optimum düzeyde elde edilmiştir.
}

Anahtar Kelimeler- Akustik, Laboratuvar, Sesin Nesnel Parametreleri, Simülasyon

1*Sorumlu yazar iletişim: mkavraz@ktu.edu.tr (https://orcid.org/0000-0001-9556-1916)

Mimarlık Bölümü, Karadeniz Teknik Üniversitesi, KTÜ Mimarlık Fakültesi Mimarlık Bölümü, TRABZON

2İletișim: oznurylz@hotmail.com (https://orcid.org/0000-0002-7197-2005)

Mimarlık Bölümü, Karadeniz Teknik Üniversitesi, KTÜ Mimarlık Fakültesi Mimarlık Bölümü, TRABZON 


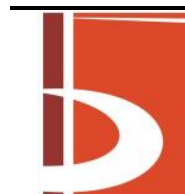

\title{
Evaluation Of The Laboratories In Terms Of Objective Parameters Of Sound: KTÜ Case
}

\begin{abstract}
In this study, Computer Laboratory in Physics Department and Analytical Chemistry Laboratory in Chemistry Department in KTU were examined acoustically. First of all, the acoustic evaluations of the current situation of the spaces were made according to the objective parameters of sound; reverberation time (RT), early fall time (EDT), prominence (D50), according to the intelligibility index of sound (STI). In the study, three-dimensional simulation technique method was applied and ODEON version 10 Acoustic Software was used as simulation program. The three-dimensional model was prepared in SketchUp8. In order to optimize to the values outside of the optimum range as acoustic, material changes were made on the surfaces of the spaces and all objective parameters were obtained at the optimum level.
\end{abstract}




\section{GİRIŞ}

Eğitim; bireyin davranışlarında, kendi yaşantısı yoluyla ve kasıtlı olarak istenilen yönde değişim gösterme sürecidir [1]. Eğitim etkinliklerinin yapıldığı ve temel fonksiyonu bilgi aktarma olan mekanların yapı fiziği gereksinimi bakımından konforlu koşullara ve donanıma sahip olması, eğitim kalitesini de olumlu yönde etkilemektedir. Bu anlamda, eğitim sürecinin devamlılı̆̆ ve kalitesinin sürdürülebilirliği açısından, eğitim faaliyetlerinin gerçekleştiği mekanların işitsel konfor koşulları yani akustik kalitesi en önemli tasarım parametreleri arasında yer almaktadır [2]. Mekanların akustik kalitesinin belirlenebilmesi için ölçme, bilgisayar simülasyon ve maket modelleme teknikleri yöntemleriyle denetimler gerçekleştirilebilmektedir. Özellikle tasarım aşamasında olan mekanlar için yaygın şekilde bilgisayar simülasyon tekniği kullanılmaktadır. Yapılan denetimler uygulamaya yönelik olduğu gibi bilimsel çalışmalar kapsamında da yapılmaktadır. Atça vd., (2013) tarafından yapılan çalışmada, İzmir İleri Teknoloji Enstitüsü Matematik Bölümü Amfisinin işitsel, görsel ve isıl konfor koşullarına ilişkin problemleri incelenmiştir. Çalışmada, bu problemlerin başarım odaklı tasarım yöntemi ile yani daha tasarım aşamasındayken benzetim araçları (simülasyon) kullanılarak kolaylıkla öngörülebileceği ve önlenebileceği ortaya konulmuştur [3]. Karaman ve Üçkaya (2015) tarafindan yapılan çalışmada, Dokuz Eylül Üniversitesi Mimarlık Fakültesi'nde bir adet stüdyo ve bir adet dersliğin mevcut durumdaki hacim akustiği koşulları öznel ve nesnel yöntemler kullanarak belirlenmiş ve elde edilen sonuçlar doğrultusunda çözüm önerileri geliştirilmiştir [2]. Özçetin vd., (2015) tarafından yapılan çalışmada, Bozok Üniversitesi MühendislikMimarlık Fakültesi Mimarlık Bölümü'nde yer alan sınıfların mevcut durumları akustik konfor koşulları açısından yerinde ölçüm metodu ile incelenmiş, optimum olmayan koşulların iyileştirilmesi için sürdürülebilir yapı malzemelerin kullanılmasına yönelik önerilerde bulunulmuştur [4].

Bu çalışma kapsamında, Karadeniz Teknik Üniversitesi Kanuni Kampüsü'nde yer alan Fizik Bölümü Bilgisayar Laboratuvarı ile Kimya Bölümü Analitik Kimya Laboratuvarının akustik özellikleri ODEON version 10 bilgisayar programında belirlenerek mevcut durum için akustik sorunlar ortaya konulmuş ve sonraki süreçte bu sorunlar çözülmüştür. Bu bağlamda reverberasyon süresi $(\mathrm{RT})$, erken düşme süresi $(\mathrm{EDT})$, belirginlik $\left(\mathrm{D}_{50}\right)$ ve sesin anlaşılabilirlik indeksi (STI) nesnel parametreleri değerlendirilmiştir.

Kaynağından yayılan sesin mekan içindeki yansımalarla birlikte denge konumuna gelmesinden sonra, ses kaynağının sönümlenmesini takiben düzeyinin $60 \mathrm{~dB}$ azalıncaya kadar geçen süre Reverberasyon Süresi (RT) olarak ifade edilmektedir [5]. Yine aynı şekilde ses kaynağının sönümlenmesini takiben düzeyinin $10 \mathrm{~dB}$ azalıncaya kadar geçen sürenin 6 katı Erken Düşme Süresi (EDT) olarak ifade edilmektedir [6]. Bir mekanda ses kaynağının sönümlenmesinden sonraki $50 \mathrm{msn}$ içinde yansıyarak alıcıya ulaşan seslerin enerjisinin alıcıya yansıyarak ulaşan toplam seslerin enerjisine oranı Belirginlik $\left(D_{50}\right)$ olarak ifade edilmektedir [7]. Sesin Anlaşılabilirlik Endeksi (STI) ise konuşmadaki net olarak anlaşılabilen hecelerin oranına odaklanan bir parametredir [8].

\section{YAPILAN ÇALIŞMALAR}

Çalışma kapsamında öncelikle laboratuvarların rölöveleri alınmış, iç mekan yüzey kaplama malzemeleri belirlenmiş ve üç boyutlu modelleri SketchUp8'de hazırlanmıştır. Boyu 18,50 m, eni 8,70 m, yüksekliği 3,10 m olan Fizik Bölümü Bilgisayar Laboratuvarının hacmi $453 \mathrm{~m}^{3}$ tür. Laboratuvar 48 kişi kapasitesinde olup, kişi başına yaklaşı $1,10 \mathrm{~m}^{3}$ hacim düşmektedir. Dikdörtgen prizma formundaki laboratuvarın zemini seramik, duvarların ve tavanın yüzeyleri ise sıva üzerine boya kaplıdır. Laboratuvarın boyu doğrultusunda; koridor duvarındaki iki kolon arasında, sadece kanadı ahşap cam bir kapı, cephe duvarında ise kolonlar arasında pencere yer almaktadır. Eni doğrultusundaki duvarda projektör perdesi bulunmaktadır. Şekil 1'de Bilgisayar Laboratuvarına ait üç boyutlu modeller yer almaktadır.

Boyu 15,75 m, eni 13,50 m, yüksekliği 3,56 m olan Kimya Bölümü Analitik Kimya Laboratuvarının hacmi $728 \mathrm{~m}^{3}$ tür. Laboratuvar 80 kişi kapasitesinde olup, kişi başına yaklaşı $9,1 \mathrm{~m}^{3}$ hacim düşmektedir. Dikdörtgen prizma formundaki laboratuvarın zemini dökme mozaik, duvarların ve tavanın yüzeyleri ise sıva 
üzerine boya kaplıdır. Fakat tavanın orta kısmı, ahşap malzemeyle asma tavan olarak uygulanmıştır. Laboratuvarın eni doğrultusunda; koridor duvarında bir adet cam kapı, diğer duvarında ise yazı tahtası ve pano yer almaktadır. Dış cephedeki her iki duvarında kolonlar arasında pencere yer almaktadır. Aydınlatma elemanı olarak sıva üstü aydınlatma armatürü kullanılmıştır. Şekil 1'de Analitik Kimya Laboratuvarına ait üç boyutlu modeler yer almaktadır.
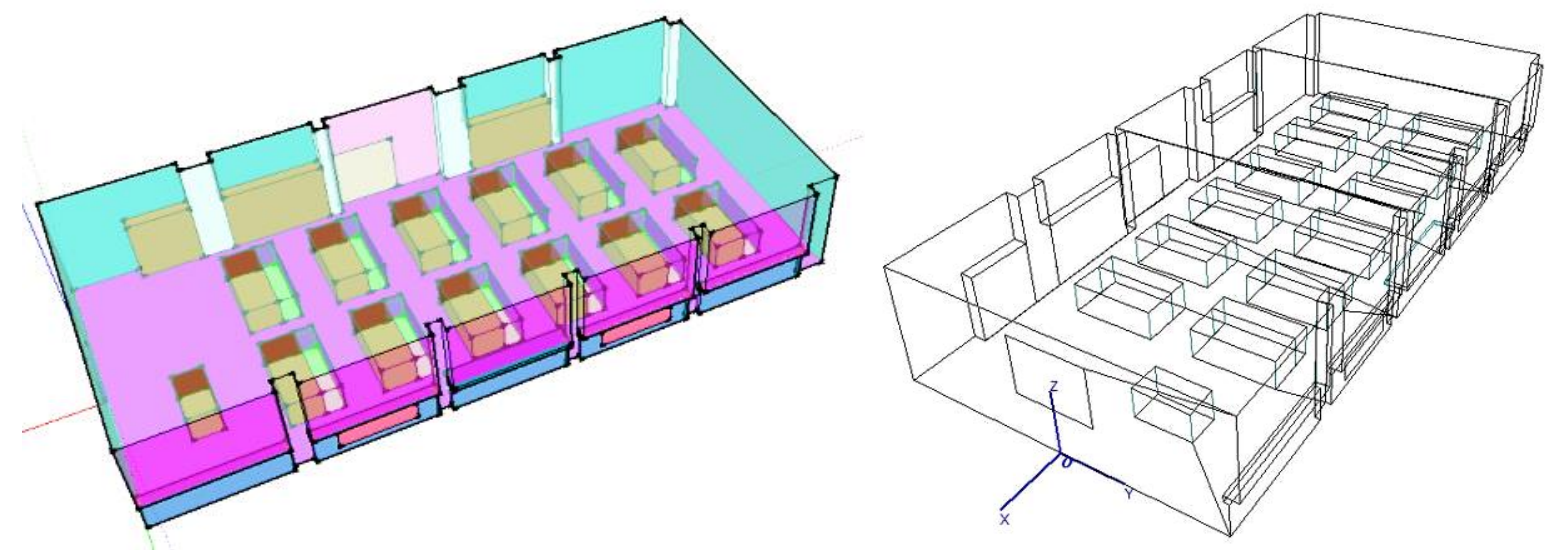

Fizik Bölümü Bilgisayar Laboratuvarı
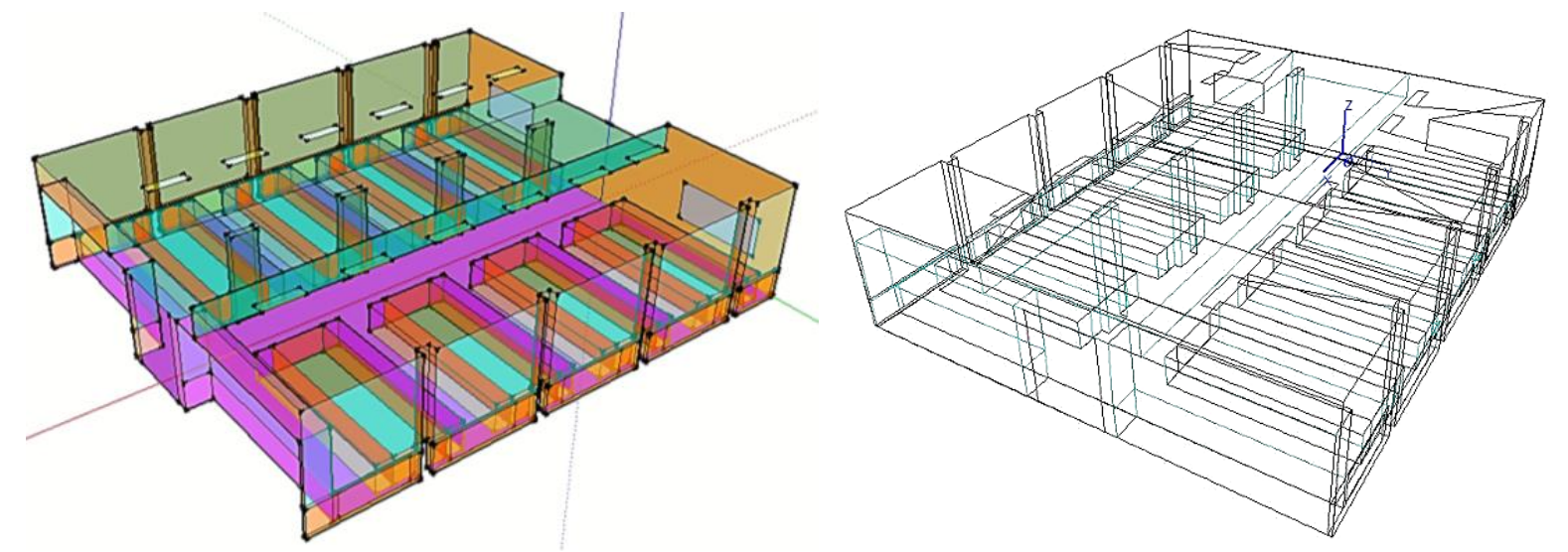

Kimya Bölümü Analitik Kimya Laboratuvarı

Şekil 1. Laboratuvarların Odeon v.10 için hazırlanan modelleri

Laboratuvarların iç mekan yüzeylerinde kullanılan kaplama malzemeleri Tablo 1 ve Tablo 3'de yer almaktadır. Optimum aralıkta elde edilemeyen nesnel parametre değerlerinin optimum aralıkta elde edilebilmesi amacıyla Fizik Bölümü Bilgisayar Laboratuarının iyileştirme çalışması için değiştirilen malzemeler ise Tablo 2'de yer almaktadır. Optimum aralık değerlendirilmesi $500 \mathrm{~Hz}$ (orta frekans bölgesi) için gerçekleştirilmiştir. 
e-ISSN: 2458-7575 (http://dergipark.gov.tr/bseufbd)

Tablo 1. Fizik Bölümü Bilgisayar Laboratuarının iç mekan yüzeylerinde kullanılan malzemeler ve $63-8000 \mathrm{~Hz}$ oktav bant frekans aralığındaki ses yutma katsayıları

\begin{tabular}{|c|c|c|c|c|c|c|c|c|c|c|c|}
\hline \multirow{3}{*}{ NO } & \multirow{3}{*}{ Yüzey } & \multirow{3}{*}{$\begin{array}{l}\text { Malzeme } \\
\text { Kodu }\end{array}$} & \multirow{3}{*}{ Malzeme } & \multicolumn{8}{|c|}{ Ses yutma Katsayıları } \\
\hline & & & & 63 & 125 & 250 & 500 & 1000 & 2000 & 4000 & 8000 \\
\hline & & & & $\mathrm{Hz}$ & $\mathrm{Hz}$ & $\mathrm{Hz}$ & $\mathrm{Hz}$ & $\mathrm{Hz}$ & $\mathrm{Hz}$ & $\mathrm{Hz}$ & $\mathrm{Hz}$ \\
\hline 2 & Tavan & $102^{*}$ & B.A.+Siva+Boya & 0.01 & 0.01 & 0.01 & 0.01 & 0.02 & 0.02 & 0.02 & 0.02 \\
\hline 3 & Tezgah & $2001^{*}$ & Mermer Malzeme & 0.01 & 0.01 & 0.01 & 0.01 & 0.01 & 0.02 & 0.02 & 0.02 \\
\hline 4 & Duvar & $1001^{*}$ & Tuğla+Sıva+Boya & 0.02 & 0.02 & 0.03 & 0.03 & 0.04 & 0.05 & 0.07 & 0.07 \\
\hline 6 & Dinleyici & $11008^{*}$ & Öğrenci & 0.62 & 0.62 & 0.72 & 0.8 & 0.83 & 0.84 & 0.85 & 0.85 \\
\hline 7 & Pencere & $10001^{*}$ & Tek cam & 0.18 & 0.18 & 0.06 & 0.04 & 0.03 & 0.02 & 0.02 & 0.02 \\
\hline 9 & $\begin{array}{l}\text { Öğrenci } \\
\text { Masası }\end{array}$ & $3004^{*}$ & Ahşap & 0.15 & 0.15 & 0.11 & 0.1 & 0.07 & 0.06 & 0.07 & 0.07 \\
\hline 10 & Kap1 & $10007^{*}$ & Ahşap & 0.14 & 0.14 & 0.1 & 0.06 & 0.08 & 0.1 & 0.1 & 0.1 \\
\hline 11 & $\begin{array}{l}\text { Kalorifer } \\
\text { Peteği }\end{array}$ & $5000^{*}$ & Metal & 0.4 & 0.3 & 0.25 & 0.2 & 0.1 & 0.1 & 0.15 & 0.15 \\
\hline 12 & Denizlik & $14308^{* *}$ & Dökme mozaik & 0.01 & 0.01 & 0.01 & 0.015 & 0.02 & 0.02 & 0.02 & 0.02 \\
\hline 13 & $\begin{array}{l}\text { Zemin } \\
\text { Döșemesi }\end{array}$ & $14307^{* * *}$ & Seramik & 0.01 & 0.01 & 0.01 & 0.01 & 0.02 & 0.02 & 0.02 & 0.02 \\
\hline 14 & Perde & $8005^{*}$ & Pamuklu kumaş & 0.3 & 0.3 & 0.45 & 0.65 & 0.56 & 0.59 & 0.71 & 0.71 \\
\hline
\end{tabular}

Tablo 2. Fizik Bölümü Bilgisayar Laboratuarının iyileştirme çalıșması için değiștirilen malzemeler ve 63-8000 Hz oktav bant frekans aralığındaki ses yutma katsayıları

\begin{tabular}{|c|c|c|c|c|c|c|c|c|c|c|c|}
\hline \multirow[b]{2}{*}{ NO } & \multirow[b]{2}{*}{ Yüzey } & \multirow[b]{2}{*}{$\begin{array}{l}\text { Malzeme } \\
\text { Kodu }\end{array}$} & \multirow[b]{2}{*}{ Malzeme } & \multicolumn{8}{|c|}{ Ses yutma Katsayıları } \\
\hline & & & & $\begin{array}{l}63 \\
\mathrm{~Hz}\end{array}$ & $\begin{array}{l}125 \\
\mathrm{~Hz}\end{array}$ & $\begin{array}{l}250 \\
\mathrm{~Hz}\end{array}$ & $\begin{array}{l}500 \\
\mathrm{~Hz}\end{array}$ & $\begin{array}{c}1000 \\
\mathrm{~Hz}\end{array}$ & $\begin{array}{c}2000 \\
\mathrm{~Hz}\end{array}$ & $\begin{array}{c}4000 \\
\mathrm{~Hz}\end{array}$ & $\begin{array}{c}8000 \\
\mathrm{~Hz}\end{array}$ \\
\hline 2 & Tavan & 14302 & $\begin{array}{l}\text { Taş yünü } \\
\text { karo levha }\end{array}$ & 0.28 & 0.29 & 0.33 & 0.53 & 0.73 & 0.86 & 0.92 & 0.92 \\
\hline 13 & $\begin{array}{l}\text { Zemin } \\
\text { Döşemesi }\end{array}$ & 7004 & Halı & 0.02 & 0.02 & 0.06 & 0.14 & 0.37 & 0.6 & 0.65 & 0.65 \\
\hline 15 & $\begin{array}{l}\text { Aydinlatma } \\
\text { Elemanı }\end{array}$ & 14306 & $\begin{array}{l}\text { Sıva altı } \\
\text { aydınlatma } \\
\text { armatürü }\end{array}$ & 0.2 & 0.12 & 0.1 & 0.04 & 0.03 & 0.03 & 0.02 & 0.02 \\
\hline
\end{tabular}


Tablo 3. Kimya Bölümü Analitik Kimya Laboratuarının iç mekan yüzeylerinde kullanılan malzemeler ve 63$8000 \mathrm{~Hz}$ oktav bant frekans aralığındaki ses yutma katsayıları

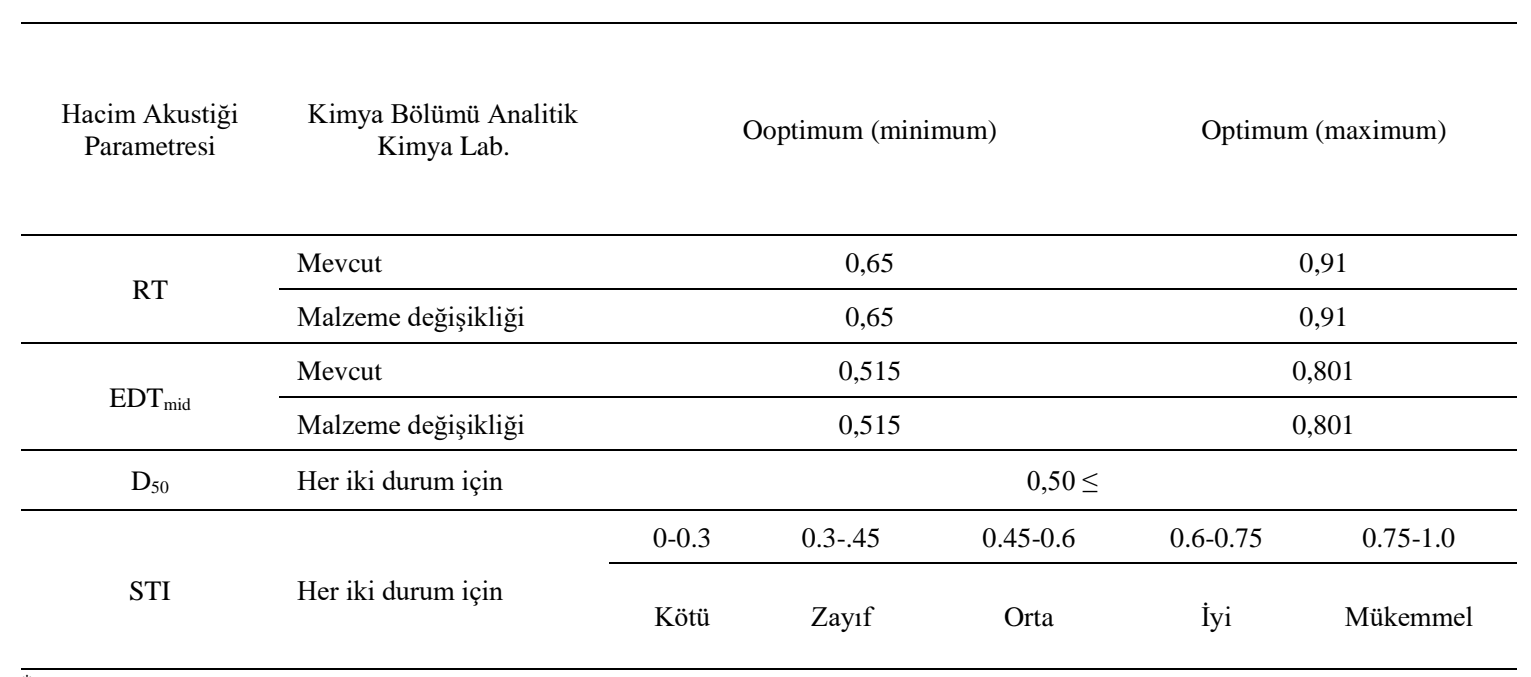

*: $[9]$

** : [10]

Üç boyutlu modelleri hazırlanan laboratuvarlar Odeon Version 10 simülasyon programına aktarılmış ve program kapsamında sırasıyla aşağıdaki işlemler gerçekleştirilmiştir;

Öncelikle model yüzeylerine genel malzeme ataması yapılmış, yüzeylerin birleşim hatlarından ses kaçışı kontrol edilmiş ve sonrasında mevcut yüzeylerde var olan malzemelerin atamaları yapılmıştır. Global reverberasyon süresi elde edildikten sonra oda akustiği hesap parametrelerine ait değerlerin atamaları gerçekleştirilmiştir. Program koşturulduktan sonra sesin nesnel parametrelerine ait sayısal değerler elde edilmiştir [11].

Simülasyon programında noktasal ses kaynağı kullanılmış olup kaynak; aks ekseni üzerinde, sahne zemininden $1.50 \mathrm{~m}$. yükseklikte ve sahne önünden $1.5 \mathrm{~m}$. arka duvar yönünde konumlandırılmıştır. Çalışma düzleminde öğrencilerin konumu $0.50 \mathrm{x} 0.50 \mathrm{~m}$. gridler şeklinde yerleştirilirken alıcıların konum yükseklikleri zemin düzleminden $1.20 \mathrm{~m}$. üst kot olarak belirlenmiştir.

\section{SESINN NESNEL PARAMETRE DEĞERLERİ}

Program çalıştırıldıktan sonra sesin nesnel parametre değerlerine ait elde edilen sonuçlar öncelikle optimum değer aralıkları ile karşılaştırılmıştır. Sonrasında ise optimum sınır değerler dışında kalan nesnel parametre değerlerinin optimum düzeylerde elde edilebilmesi için mekan yüzeylerinde malzeme değişiklikleri yapılmıştır.

I. $\quad$ Fizik Bölümü Bilgisayar Laboratuvarının Mevcut Durumu için Elde Edilen Sesin Nesnel Parametrelerinin Değerlendirilmesi

Fizik Bölümü Bilgisayar Laboratuvarının akustik konfor koşullarının incelenmesi için kullanılan sesin nesnel parametrelerine ait optimum değer aralıkları, mekanın mevcut durumu ve iyileştirme çalışması doğrultusunda yapılan malzeme değişikliğinden sonraki durumu için Tablo 4'de verilmiştir. 
Tablo 4. Fizik Bölümü Bilgisayar Laboratuarının mevcut ve malzeme değişikliğinden sonraki durumu için sesin nesnel parametrelerine ait optimum değer aralıkları, [12], [13], [7], [14], [5]

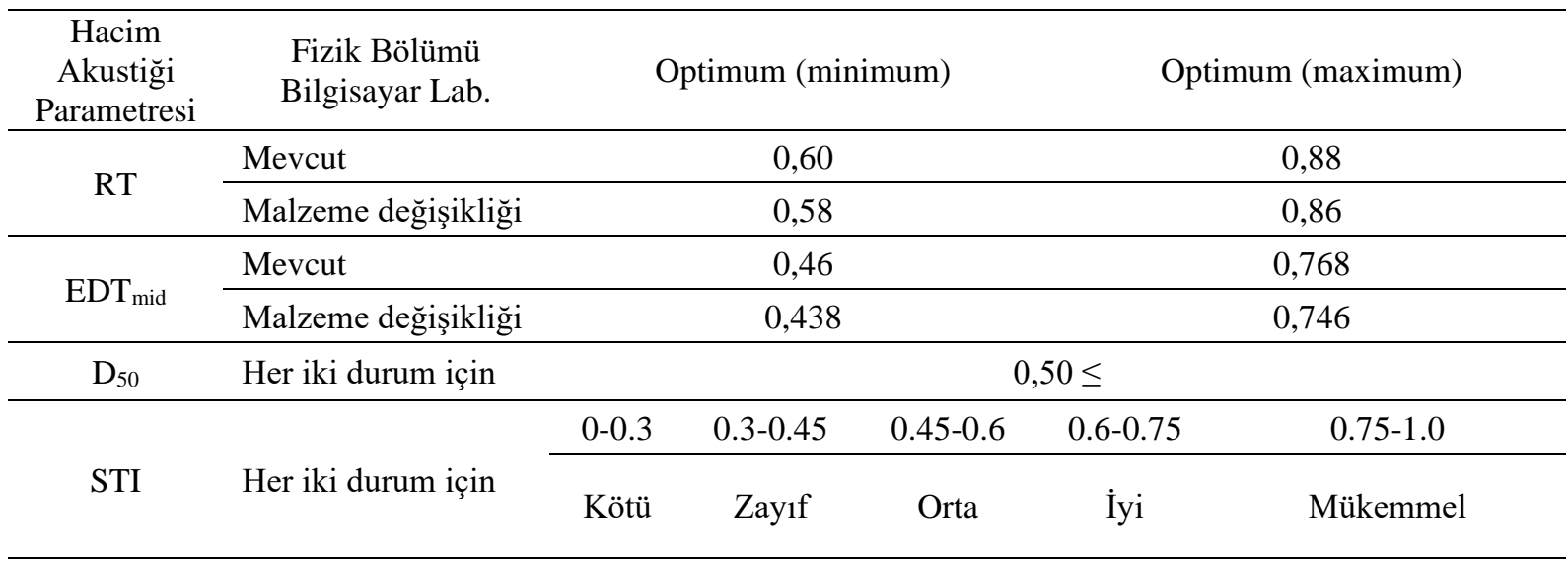

a. Reverberasyon Süresi (RT): Bilgisayar Laboratuvarının mevcut durumu için RT değeri $500 \mathrm{~Hz}$ 'de (orta frekans bölgesi) 0,86 sn. olarak elde edilmiştir (Şekil 2). Orta hacimli mekan kapsamında incelenen ve $453 \mathrm{~m}^{3}$ hacme sahip olan laboratuvarın, orta frekans bölgesinde optimum RT değeri 0,60 ile 0,88 sn. aralığındadır (Tablo 4). Belirtilen değer aralıklarına göre, RT değeri optimum düzeyde elde edilmiştir.

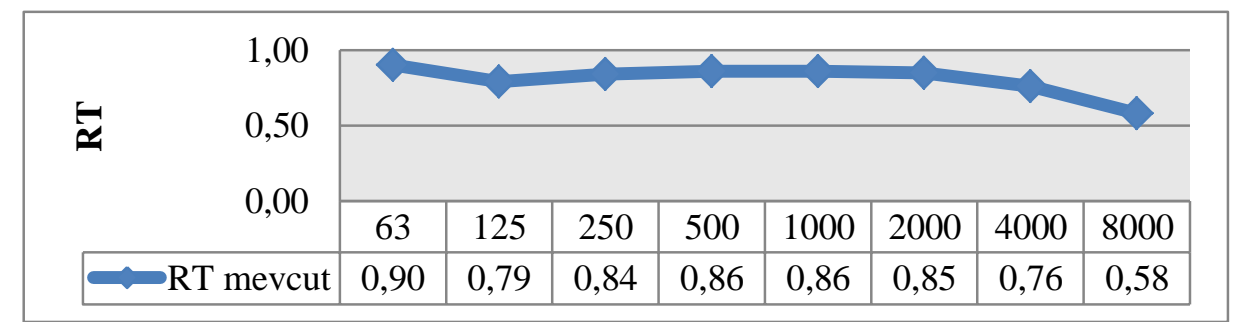

Şekil 2. Oktav band frekanslarda elde edilen RT değerleri

b. Erken Düşme Süresi (EDT): Bilgisayar Laboratuvarının mevcut durumu için EDT değeri $500 \mathrm{~Hz}$ 'de (orta frekans bölgesi) 0,89 sn. olarak elde edilmiştir (Şekil 3). Optimum EDT değeri ise, orta frekans bölgesinde 0,46 ile 0,768 sn. aralığındadır (Tablo 4). Belirtilen değer aralıklarına göre, laboratuvarın mevcut durumu için EDT değeri, optimum düzeyin üzerinde elde edilmiştir.

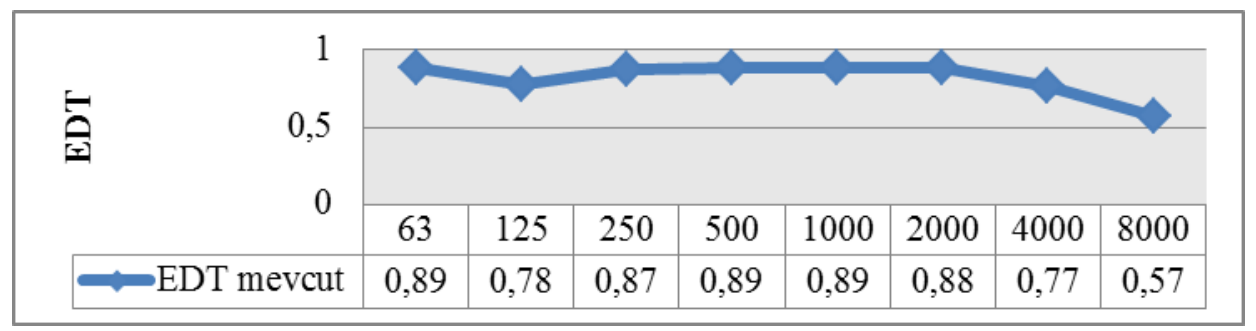

Şekil 3. Oktav band frekanslarda elde edilen EDT değerleri 
c. Ayırt Edilebilirlik $\left(D_{50}\right)$ : Bilgisayar Laboratuvarının mevcut durumu için $\mathrm{D}_{50} 0,57$ olarak elde edilmiştir (Şekil 4). Bu değer $\mathrm{D}_{50}$ optimum alt sınır değerinin üzerindedir. Laboratuvarın mevcut durumu için \%50'nin üzerinde olan $\mathrm{D}_{50}$ parametresine göre, \%90 konuşmanın belirginliğinin yeterli düzeyde olduğu belirlenmiştir (Tablo4).

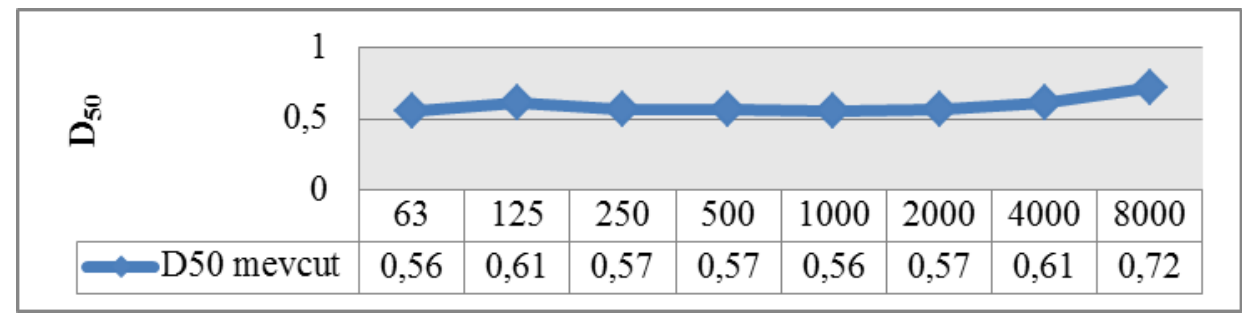

Şekil 4. Oktav band frekanslarda elde edilen D50 değerleri

d. Ses Iletim Índeksi (STI): Bilgisayar Laboratuvarının mevcut durumu için STI değeri 0,63 olarak elde edilmiştir (Şekil 5). Elde edilen STI değeri anlaşılabilirliğin iyi düzeyde olduğu 0,60 ile 0,75 aralığındadır (Tablo 4).

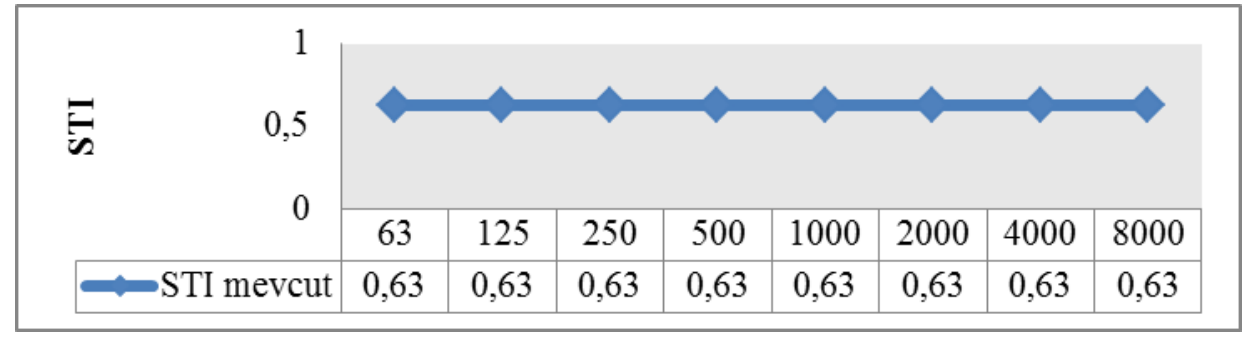

Şekil 5. Oktav band frekanslarda elde edilen STI değerleri

\section{Fizik Bölümü Bilgisayar Laboratuvarı için Iyileştirme Çalışması}

Fizik Bölümü Bilgisayar Laboratuvarı için elde edilen EDT değerini optimum düzeye, $\mathrm{D}_{50}$ ve STI değerlerini daha iyi düzeylere getirmek amacıyla mekan yüzeylerinde bazı malzeme değişiklikleri yapılmıştır. Malzeme değişikliğinde genel olarak alçak frekanslardan yüksek frekanslara doğru ses yutuculukları giderek artış gösteren malzemeler seçilmiştir. Döşemede: halı, tavanda: taş yünü karo levhalar kullanılmıştır. Tavanda kullanılan taş yünü asma tavan uygulaması ile uyumlu şekilde, sıva altı aydınlatma armatürü kullanılmıştır (Tablo 2). İyileştirme çalışması kapsamında Bilgisayar Laboratuvarının Sketchup 8 programı ile yeniden modellemesi yapılmış ve ODEON V10 programında simülasyon işlemi gerçekleştirilmiştir. Elde edilen sesin nesnel parametre değerlerine göre sonuçlar tekrar değerlendirilmiştir.

a. Reverberasyon Süresi (RT): Malzeme değişikliği ile meydana gelen tavan formundaki değişiklik sonucunda mekanın hacmi $400 \mathrm{~m}^{3}$ 'e düşmüştür. Belirtilen hacme sahip olan bir mekandaki optimum RT değerinin 0,58 ile 0,86 sn. aralığında olması gerekmektedir (Tablo 4). Bu değer aralığına göre, malzeme değişikliği sonrasında da RT değeri 0,62 sn. ile optimum düzeyde elde edilmiştir (Şekil 6). 
e-ISSN: 2458-7575 (http://dergipark.gov.tr/bseufbd)

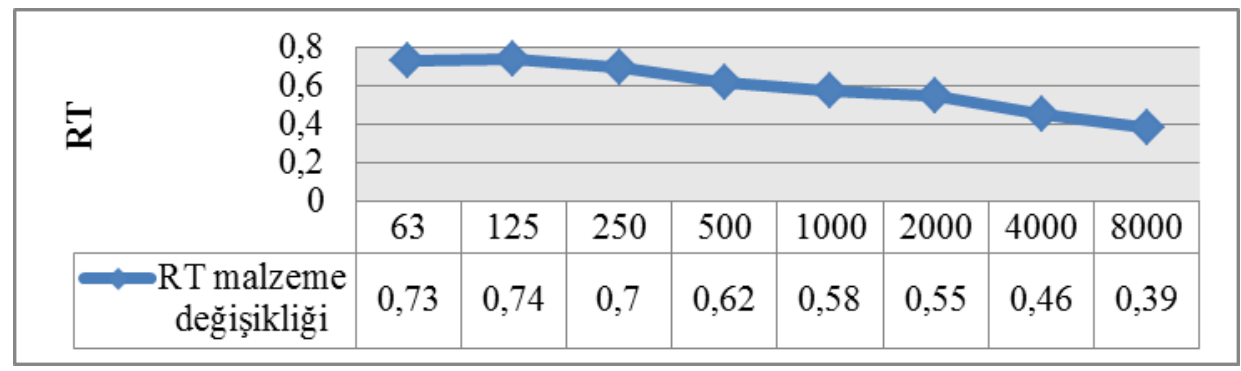

Şekil 6. Oktav band frekanslarda elde edilen RT değerleri

b. Erken Düşme Süresi (EDT): Laboratuvar için malzeme değişikliğinden sonraki optimum EDT değeri 0,438 ile $0,746 \mathrm{sn}$. aralığındadır (Tablo 4). Dersliğin mevcut durumu için optimum değer aralıklarında olmayan EDT değeri $(0,89 \mathrm{sn}$.), malzeme değişikliğinden sonra $0,54 \mathrm{sn}$. değeri ile optimum düzeyde elde edilmiştir (Şekil 7).

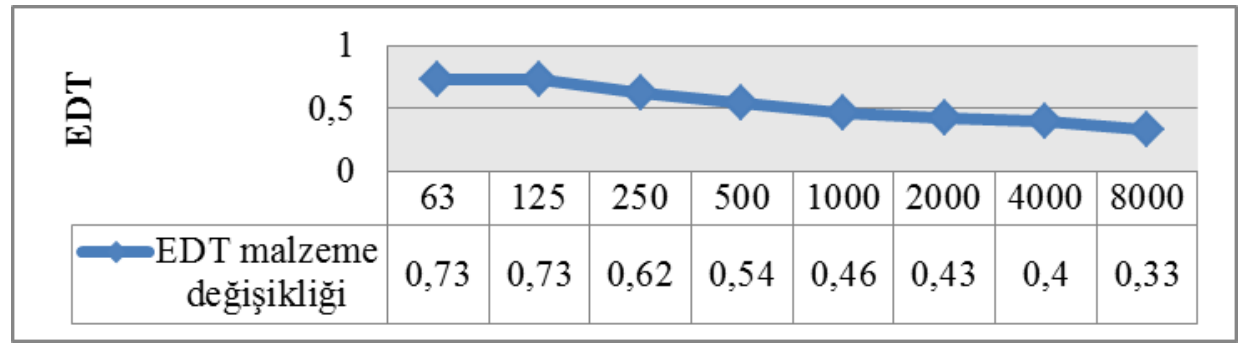

Şekil 7. Oktav band frekanslarda elde edilen EDT değerleri

c. Ayırt Edilebilirlik $\left(D_{50}\right)$ : Malzeme değişikliğinden sonra elde edilen $\mathrm{D}_{50}$ değerinde $(0,75)$ mevcut durumdaki $\mathrm{D}_{50}$ değerine $(0,57)$ göre artış meydana gelmiştir (Şekil 8). Değişiklik sonrasında, laboratuvar için konuşmanın belirginliğinin mevcut duruma göre daha iyi olduğu belirlenmiştir.

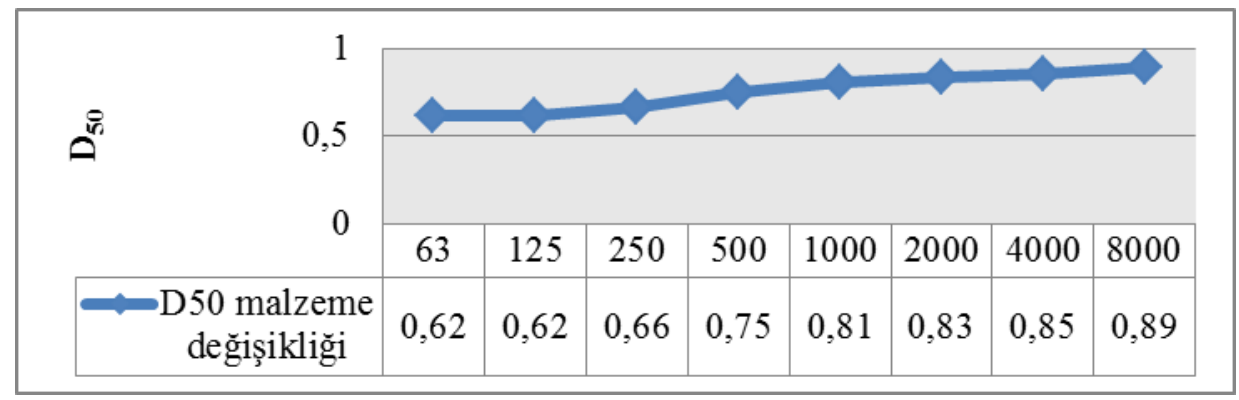

Şekil 8. Oktav band frekanslarda elde edilen D50 değerleri

d. Ses Illetim İndeksi (STI): Laboratuvarda yapılan malzeme değişikliğinden sonra elde edilen STI değeri $(0,74)$ anlaşılabilirliğin iyi düzeyde olduğu 0,60 ile 0,75 değer aralığındadır ve mevcut durumdaki STI değerine $(0,63)$ göre değerinde artış elde edilmiştir (Şekil 9). 


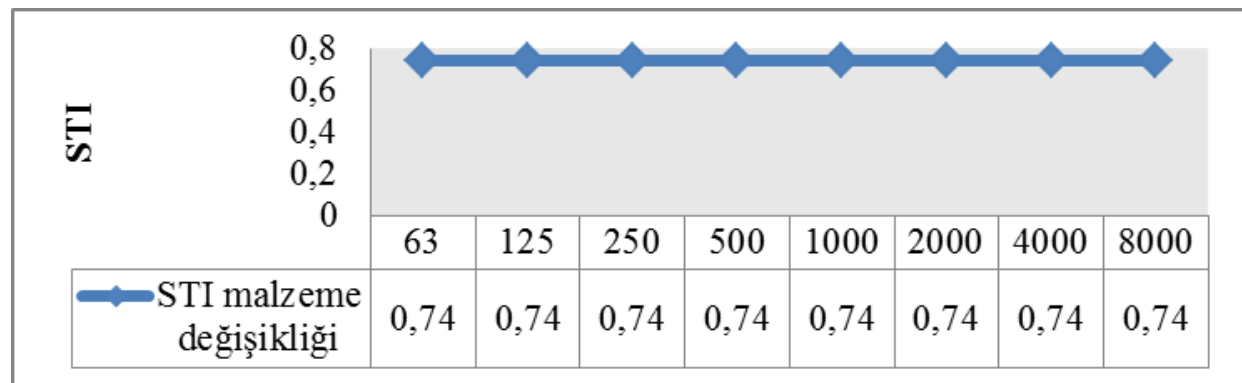

Şekil 9. Oktav band frekanslarda elde edilen STI değerleri

\section{Kimya Bölümü Analitik Kimya Laboratuvarının Mevcut Durumu için Elde Edilen Sesin Nesnel} Parametrelerinin Değerlendirilmesi

Kimya Bölümü Analitik Kimya Laboratuvarının akustik konfor koşullarının incelenmesi için kullanılan sesin nesnel parametrelerine ait optimum değer aralıkları, mekanın mevcut durumu ve iyileştirme çalışması doğrultusunda yapılan malzeme değişikliğinden sonraki durumu için Tablo 5'de verilmiştir.

Tablo 5. Kimya Bölümü Analitik Kimya Laboratuarının mevcut ve malzeme değişikliğinden sonraki durumu için sesin nesnel parametrelerine ait optimum değer aralıkları; [12], [13], [7], [14], [5]

Hacim

Akustiği

Kimya Bölümü

Parametresi

Analitik Kimya Lab.

\begin{tabular}{|c|c|c|c|c|c|c|}
\hline \multirow{2}{*}{ RT } & Mevcut & \multicolumn{3}{|c|}{0,65} & \multicolumn{2}{|c|}{0,91} \\
\hline & Malzeme değişikliği & \multicolumn{3}{|c|}{0,65} & \multicolumn{2}{|c|}{0,91} \\
\hline \multirow{2}{*}{$\mathrm{EDT}_{\text {mid }}$} & Mevcut & & 0,515 & & \multicolumn{2}{|c|}{0,801} \\
\hline & Malzeme değişikliği & & 0,515 & & \multicolumn{2}{|c|}{0,801} \\
\hline $\mathrm{D}_{50}$ & Her iki durum için & \multicolumn{5}{|c|}{$0,50 \leq$} \\
\hline \multirow{2}{*}{ STI } & \multirow{2}{*}{ Her iki durum için } & $0-0.3$ & $0.3-.45$ & $0.45-0.6$ & $0.6-0.75$ & $0.75-1.0$ \\
\hline & & Kötü & Zayıf & Orta & İyi & Mükemmel \\
\hline
\end{tabular}

a. Reverberasyon Süresi (RT): Analitik Kimya Laboratuvarının mevcut durumu içi RT değeri $500 \mathrm{~Hz}$ 'de (orta frekans bölgesi) 0,79 sn. olarak elde edilmiştir (Şekil 10). Büyük hacimli mekan kapsamında incelenen ve 728 $\mathrm{m}^{3}$ hacme sahip olan laboratuvarın, orta frekans bölgesindeki optimum RT değeri 0,65 ile 0,91 sn. aralığındadır (Tablo 5). Belirtilen değer aralıklarına göre, RT değeri optimum düzeyde elde edilmiştir. 
e-ISSN: 2458-7575 (http://dergipark.gov.tr/bseufbd)

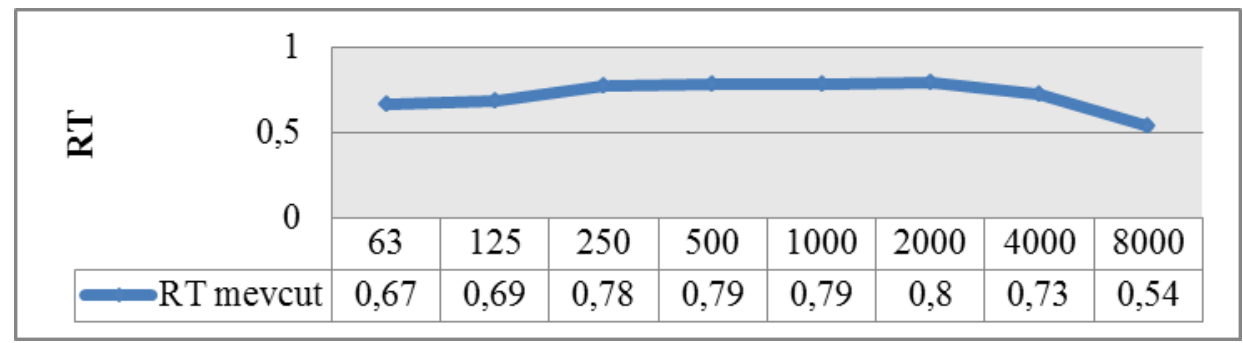

Şekil 10. Oktav band frekanslarda elde edilen RT değerleri

b. Erken Düşme Süresi (EDT): Analitik Kimya Laboratuvarının mevcut durumu için EDT değeri $500 \mathrm{~Hz}$ 'de (orta frekans bölgesi) 0,72 sn. olarak elde edilmiştir (Şekil 11). Optimum EDT değeri ise, orta frekans bölgesinde 0,515 ile 0,801 sn. aralığındadır (Tablo 5). Belirtilen değer aralığına göre, laboratuvarın mevcut durumu için EDT değeri, optimum düzeyde elde edilmiştir.

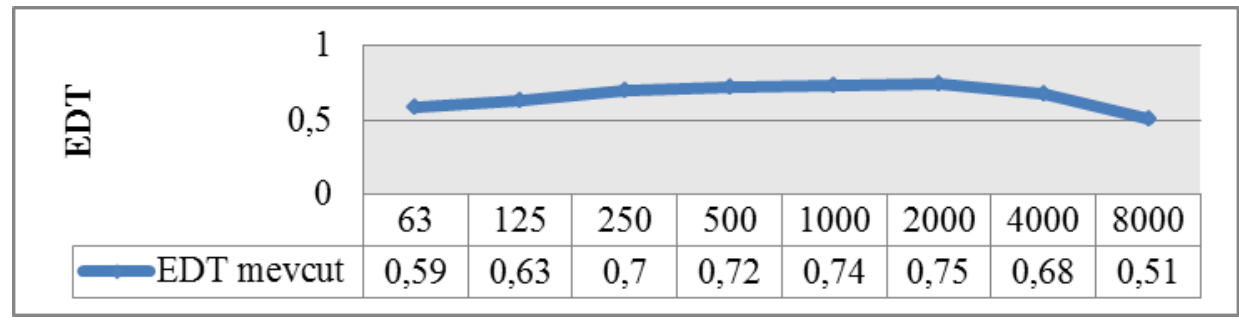

Şekil 11. Oktav band frekanslarda elde edilen EDT değerleri

c. Ayırt Edilebilirlik ( $\left.D_{50}\right)$ : Analitik Kimya Laboratuvarının mevcut durumu için $\mathrm{D}_{50}$ değeri 0,67 olarak elde edilmiştir (Şekil 12). Bu değer $\mathrm{D}_{50}$ optimum alt sınır değerin üzerindedir. Laboratuvarın mevcut durumu için \%50'nin üzerinde olan $\mathrm{D}_{50}$ parametresine göre, \%90 konuşmanın belirginliğinin yeterli düzeyde olduğu belirlenmiştir.

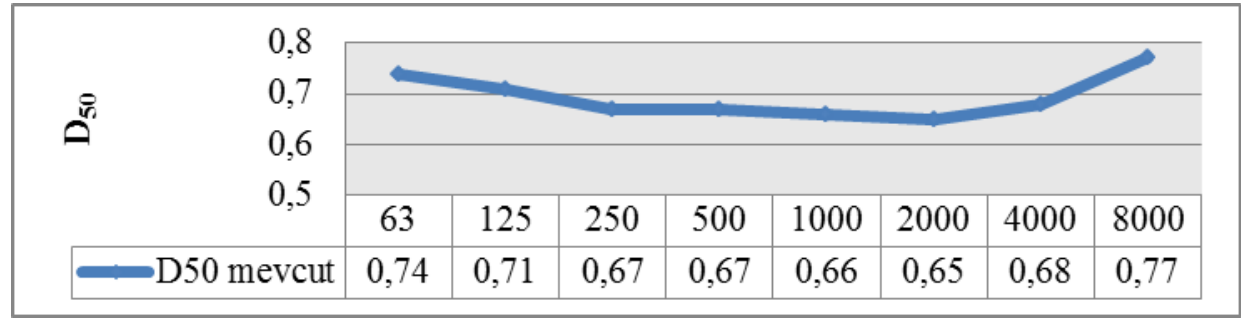

Şekil 12. Oktav band frekanslarda elde edilen D50 değerleri

d. Ses Iletim Índeksi (STI): Analitik Kimya Laboratuvarının mevcut durumu için STI değeri 0,68 olarak elde edilmiştir (Şekil 13). Elde edilen STI değeri anlaşılabilirliğin iyi düzeyde olduğu 0,60 ile 0,75 aralığındadır (Tablo 5). 


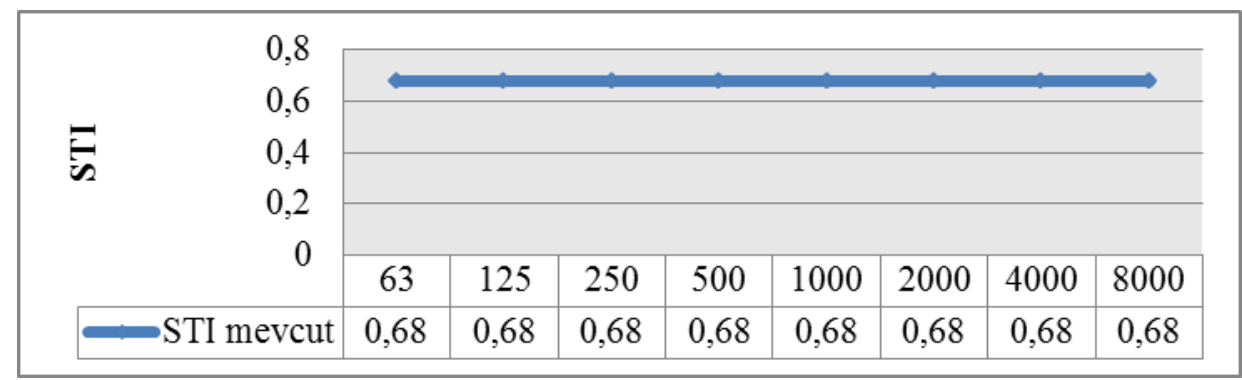

Şekil 13. Oktav band frekanslarda elde edilen STI değerleri

\section{SONUÇLAR}

KTÜ Fizik Bölümü Bilgisayar Laboratuvarı ile Kimya Bölümü Analitik Kimya Laboratuvarı ODEON version10 ile sesin nesnel parametere değerlerine bağlı olarak akustik açıdan değerlendirilmiştir. Fizik Bölümü Bilgisayar Laboratuvarı için yapılan değerlendirmede EDT değeri optimum aralık dışında elde edilmiş ve mekan yüzeylerinde yapılan değişikliklerle bu parametre değeri optimum düzeyde edilmiştir. Bunun yanı sıra D50 ve STI parametre değerleri ise daha iyi düzeylerde elde edilmişlerdir. Kimya Bölümü Analitik Kimya Laboratuvarı için elde edilen sesin nesnel parametre değerlerine göre yapılan değerlendirmede ise tüm parametrelerin optimum düzeyde olduğu belirlenmiş ve herhangi bir değişikliğe gerek duyulmadığı belirlenmiştir.

\section{TEŞEKKÜR:}

Bu çalışma, 2009.120.001.1 No’lu Proje kapsamında KTÜ - BAP Birimi tarafından desteklenmiştir. Aynı zamanda, KTÜ Mimarlık Anabilim Dalında "Eğitim Yapılarındaki İç Mekanların Bilgisayar Simülasyon Yöntemi ile Akustik Açıdan İncelenmesi, Değerlendirilmesi ve Düzenlenmesi: KTÜ Örneği” isimli Yüksek Lisans Tezi kapsamında yapılmıştır.

\section{KAYNAKLAR}

[1] Ertürk, S. (1972). Eğitim Program Geliştirme, Yelkentepe Yayını:4, Ankara.

[2] Karaman, Ö.Y. ve Üçkaya, N.B. (2015). Eğitim Mekanlarında Akustik Konfor: Dokuz Eylül Üniversitesi Mimarlık Fakültesi Örneği. Megaron, 10(4), 503-521.

[3] Atça, E., İlal, M.E., Başaran, T., Kazanasmaz, T., Arsan, Z.,D., (2013). Başarım Odaklı Tasarım: Tasarımın Erken Evrelerinde Benzetim Araçlarının Önemi, 11. Ulusal Tesisat Mühendisliği Kongresi, Nisan, İzmir, Bildiriler Kitab1: 1411-1422.

[4] Özçetin, Z., Demirel F., Pektaş S., Eminel M., 2015. Eğitim Yapılarında Sürdürülebilir Malzeme ve Akustik Konfor Koşullarının Sağlanmasına Yönelik Bir Çalışma, 2. International Sustainable Buildings Symposium, 28-30 Mayıs, Ankara, Bildiriler Kitabı: 314-317.

[5] Long, M. (2006). Architectural acoustics. New York: Elsevier Inc.

[6] ISO. (2009). Acoustics - Measurement of rooms acoustic parameters - Part 1:Performance spaces, BS EN ISO-3382-1.

[7] Barron, M. (1993). Auditorium acoustics and architectural design. London: E \& FN Spon.

[8]. Wijngaarden S. V., Jan Verhave J., Steeneken H. (2012). The speech transmission index after four decades of development. Acoustics Australia, 138, Vol. 40, No. 2. 
[9] Odeon Room Acoustics Program, Version 10 malzeme kütüphanesi.

[10] PTB (2011). Sound Absorber Materials. Physikalisch-Technische Bundesanstalt , Alman Ulusal Metroloji Enstitüsü. http://www.ptb.de/en/org/1/16/163/datenbank.htm, (15.12.2011).

[11] Kavraz, M. (2012). The Effect of Sound Diffusers on the Objective Parameters of Sound: The Multipurpose Hall of Sultanbeyli Cultural Center, American Journal of Scientific Research, Issue 57, 37-46, 2012.

[12] Sirel, Ş. (1981). Hacim akustiğinde yansışım süresi. İstanbul: Yapı Fiziği Bilim Dalı Yayınları, İDMMA Basımevi.

[13] Gade, A.C. (1989). Acoustical survey of eleven european concert halls. Denmark: The Acoustics Laboratory, Technical University of Denmark, Report No.44.

[14] Kuttruff, H. (1991). Room Acoustics, Elsevier Science Publishing, New York. 